\title{
The emerging Pannexin 1 signalome: a new nexus revealed?
}

\author{
Leigh E. Wicki-Stordeur ${ }^{1}$ and Leigh A. Swayne $e^{1,2,3,4}$ * \\ 1 Division of Medical Sciences, University of Victoria, Victoria, BC, Canada \\ ${ }^{2}$ Department of Biology, University of Victoria, Victoria, BC, Canada \\ ${ }^{3}$ Department of Biochemistry and Microbiology, University of Victoria, Victoria, BC, Canada \\ ${ }^{4}$ Department of Cellular and Physiological Sciences and Island Medical Program, University of British Columbia, Vancouver, BC, Canada
}

\author{
Edited by: \\ Christophe Altier, University of \\ Calgary, Canada

\section{Reviewed by:} \\ Michael F. Jackson, University of \\ Manitoba, Canada \\ Tuan Trang, University of Calgary, \\ Canada

\section{${ }^{*}$ Correspondence:} \\ Leigh A. Swayne, Division of Medical \\ Sciences, University of Victoria, 3800 \\ Finnerty Road, Victoria, BC V8P 5C2, \\ Canada \\ e-mail: Iswayne@uvic.ca
}

\begin{abstract}
Pannexins (Panxs) are a family of single-membrane, large-pore ion, and metabolite permeable channels. Of the three Panx proteins, Panx 1 has been most extensively studied, and has recently emerged as an exciting, clinically relevant target in many physiological and pathophysiological settings. This channel is widely expressed across various cell and tissue types; however its links to precise signaling pathways are largely unknown. Here we review the current literature surrounding presently identified Panx1-protein interactions, a critical first step to unraveling the Panx1 signalome. First we elucidate the reported associations of Panx1 with other ion channels, receptors, and channel signaling complexes. Further, we highlight recently identified Panx1-cytoskeleton interactions. Finally, we discuss the implications of these protein-protein interactions for Panx1 function in various cell and tissue types, and identify key outstanding questions arising from this work.
\end{abstract}

Keywords: Pannexin 1, Panx1, pannexins, interactome, P2X7, inflammasome, cytoskeleton

\section{WHAT IS THE VALUE OF UNRAVELING THE PANX1 SIGNALOME?}

Panx1 forms large pore channels permeable to ions and small molecules, and is a clinically relevant protein in inflammatory conditions (Kanneganti et al., 2007; Silverman et al., 2009; Gulbransen et al., 2012; Diezmos et al., 2013), stroke (Thompson et al., 2006; Bargiotas et al., 2011; Bargiotas et al., 2012; Dvoriantchikova et al., 2012), and cancer (Lai et al., 2007; Cowan et al., 2012; Penuela et al., 2012). Panx1 is ubiquitously found in many cell and tissue types throughout the body, while Panx2 and Panx 3 exhibit slightly more restricted organ and tissue expression patterns. Because of its widespread distribution, future attempts to develop Panx1based therapeutic strategies will optimally incorporate tissue/cell type specificity to minimize side effects. Knowledge of the signaling pathways in which Panx1 participates, more precisely, its unique cell- and tissue-specific protein interaction partners, will be important for the development of such targeted therapeutic strategies. Thus, not only will unraveling the web of the Panx1 signalome be key for understanding the depth and breadth of its tissue and cell-specific functions, it will also be critically important for Panx1-based drug development.

\section{PANX1 PERSPECTIVES, THEN AND NOW}

Panx1 was cloned in 1998, and the pannexin family was first described as putative gap junction proteins in 2000 (Panchin et al., 2000) based on their homology to innexins, the invertebrate gap-junction forming proteins. Of the three Panx family members, Panx1 has been the primary focus of research. A large body of work has developed the current consensus that Panx1 forms single membrane channels (recently reviewed MacVicar and Thompson, 2009; Sosinsky etal., 2011). Individual fourpass transmembrane domain Panx1 subunits come together as hexamers. Panx1 channels appear to be relatively non-selective, permitting the passage of small ions and molecules up to one kilodalton in size. Panx1 is perhaps most well-known for its role in facilitating ATP release from a variety of cell types under both physiological and pathophysiological contexts, by several mechanisms of activation (recently reviewed Sandilos and Bayliss, 2012).

There are still significant gaps in the knowledge of the molecular mechanisms regulating Panxl function and its downstream effects. Since its discovery, only a handful of studies have captured small snapshots of the Panx1 interactome. Here we unite these somewhat disparate pieces in order to develop a clearer picture of the cellular signaling network of Panxl. We also highlight data from our recent study that included the first unbiased proteomics analysis of Panxl interacting proteins (Wicki-Stordeur and Swayne, 2013). In this minireview, we have grouped these interacting proteins into two major categories: (1) ion channels, receptors, and their signaling complexes and (2) cytoskeletal proteins (summarized in Table 1; Figure 1).

\section{ION CHANNELS, RECEPTORS, AND THEIR SIGNALING COMPLEXES}

PANX1-PANNEXIN INTERACTIONS

An early starting point was other members of the Pannexin protein family (Bruzzone et al., 2005). The initial impetus for investigation into Panx-Panx interactions likely arose from a rich literature detailing the intermixing of connexins (reviewed in Koval, 2006), the vertebrate gap junction protein family. Connexins share structural similarity to pannexins, but no sequence similarity. The first identified Panx1 binding protein was its family member, Panx2 (Bruzzone et al., 2005). 
Table 1 | Summary of Panx1 protein interaction partners, supporting evidence, functional significance, and relevant references.

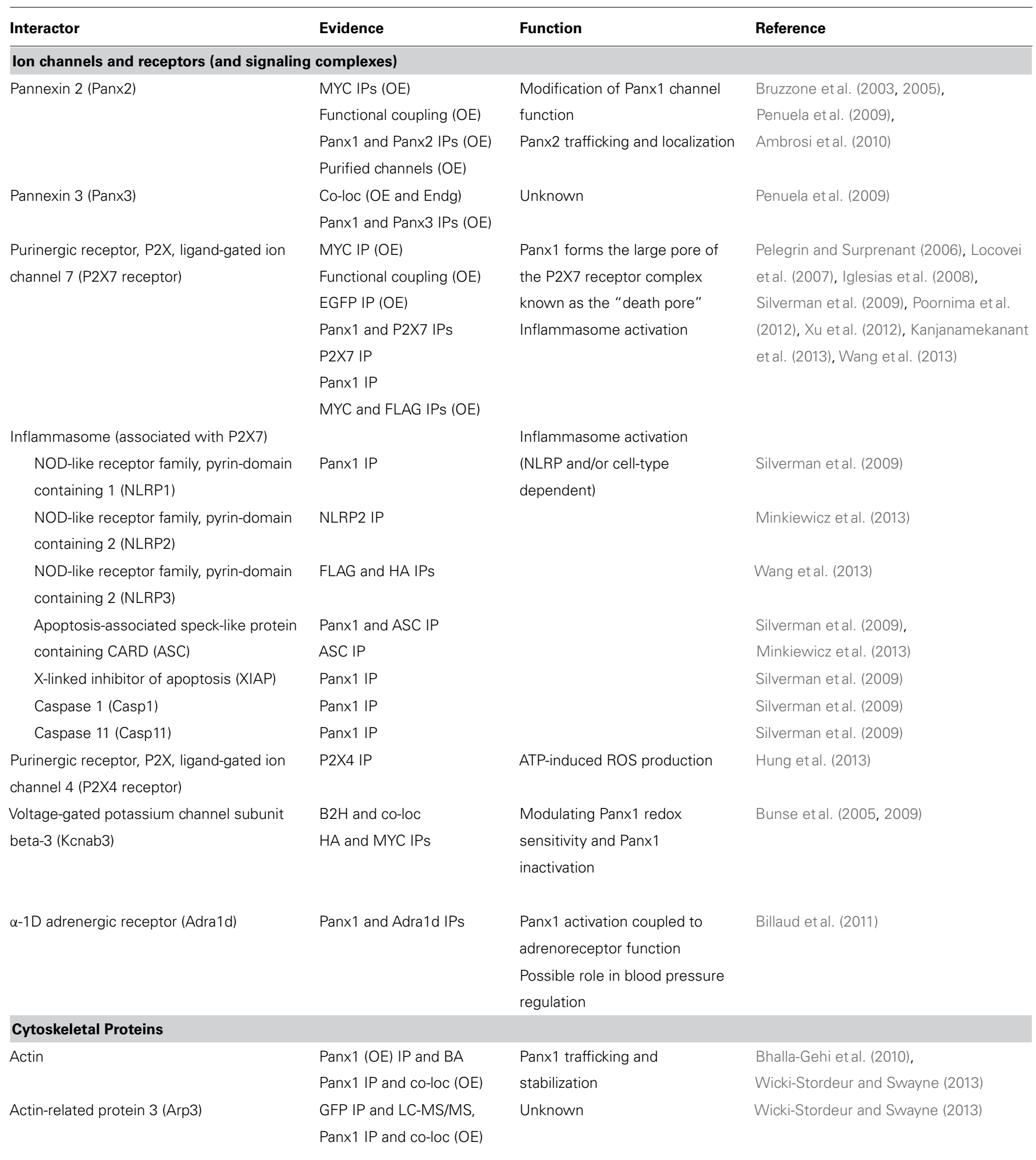

B2H, bacterial two-hybrid; BA, binding assay; Co-loc, Co-localization; Endg, endogenous; IP, immunoprecipitation; OE, overexpressed; LC-MS/MS, high performance liquid chromatography coupled to tandem mass spectrometry analysis. 


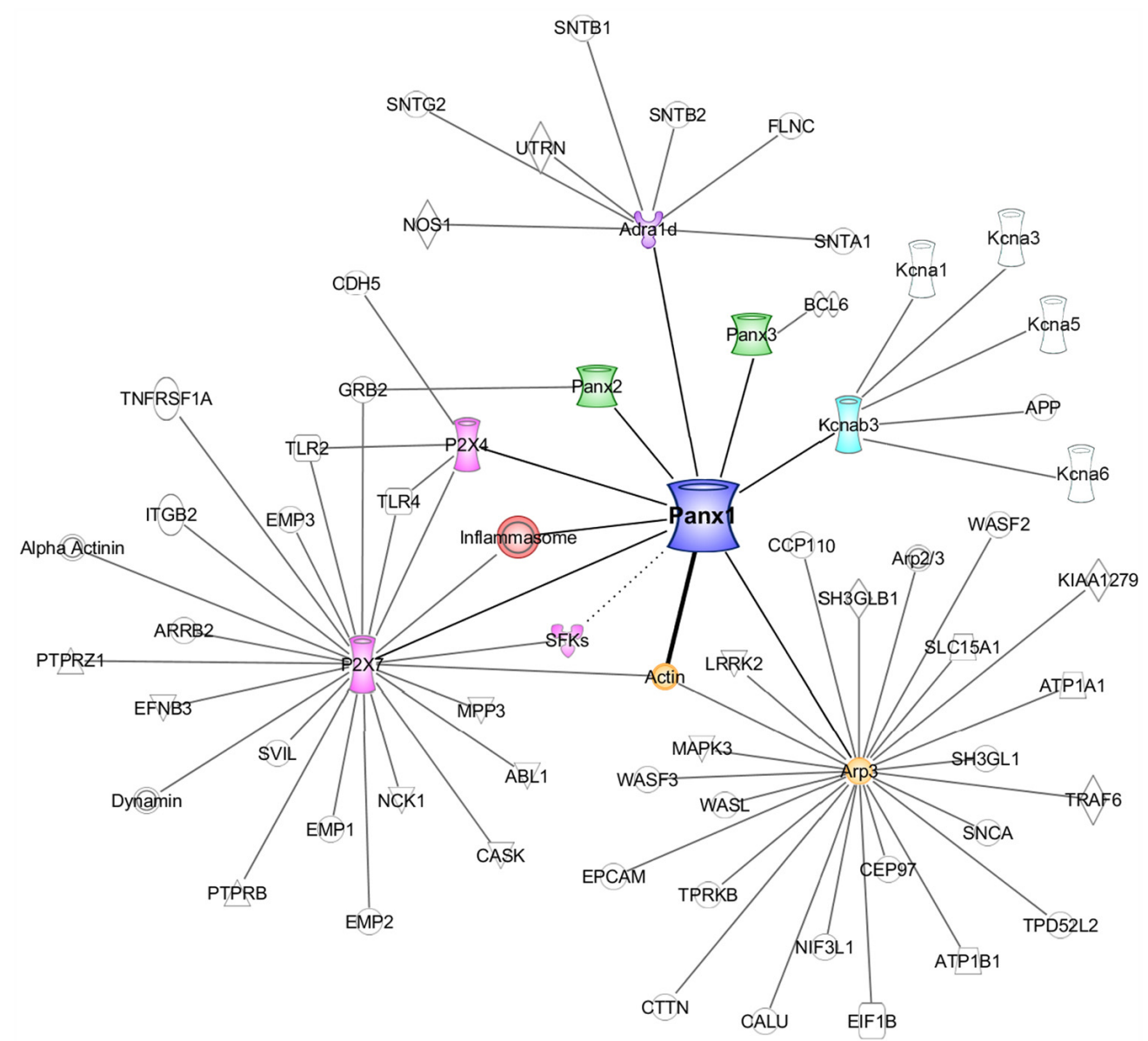

FIGURE 1 |The Panx1 interactome. A diagram generated using Ingenuity Pathways Analysis [IPA; Ingenuity Systems (Qiagen), Redwood City, CA, USA] representing a curated list of the Panx1 interacting proteins, and the subsequent IPA-derived interaction networks of these interactors (excluding actin). The thick line between Panx1 and actin represents a direct interaction. The dotted line between Panx1 and SFKs indicates a likely link between the two proteins, however, no physical interaction data is yet available.
Panx2 is a much larger protein that Panx1, owing to its exceptionally longer C-terminus. It is particularly enriched in the brain (Baranova et al., 2004). The discovery of this interaction by Bruzzone et al. (2005) arose subsequent to an earlier observation by the same group, that depolarization-evoked currents in Xenopus oocytes injected with RNA for both Panx1 and Panx2 were significantly smaller and had modified gating kinetics in comparison with currents from Xenopus oocytes injected with Panx1 RNA alone (Bruzzone et al., 2003). The RNA encoding Panx2 itself did not lead to a depolarization-activated current. The authors proposed that Panx1/Panx2 heteromerization was the underlying cause for the difference in depolarization-evoked currents. Their later discovery of the interaction between epitope-tagged Panx1 and Panx2 supported this hypothesis (Bruzzone et al., 2005).

Key questions arose from these initial findings. For these findings to be physiologically relevant, Panx 1 and Panx 2 must be found in the same cells, and need to come into close proximity. Whether Panx 1 and Panx 2 are found in the same subcellular compartments is still an open question. To date, several studies have shown that ectopically and endogenously expressed Panxl are found primarily at the cell surface, with some reports of intracellular expression. In contrast, ectopically (Lai et al., 2009; Penuela et al., 2009) and endogenously (Swayne et al., 2010; Wicki-Stordeur et al., 2013) expressed Panx2 are largely found primarily in intracellular compartments. Whether Panx2 forms functional channels at the cell membrane is contentious (but see Penuela et al., 2009). Further, if Panx2 forms functional channels, are they activated in the same way as Panxl channels? Does the interaction occur early in the secretory pathway, and could it impact on the trafficking of Panx1?

Penuela etal. (2009) later demonstrated that co-expression with Panx1 in HEK293T cells dramatically increased the cell surface expression of Panx2, measured by cell surface biotinylation and confocal microscopy. In HEK 293T cells ectopically co-expressing Panx1 and Panx2, the authors confirmed reciprocal co-precipitation of the two proteins. Interestingly, immunoprecipitation of Panx 2 co-precipitates the immature glycosylation species of Panx1 specific to the early secretory pathway (gly0 and gly1). This suggests the proteins are able to interact early in the secretory pathway, not long after translation. Somewhat paradoxically, the ability of Panx1 to increase the cell surface expression of Panx2 
suggests that Panx1/Panx2 reaches the plasma membrane. In a similar set of experiments, this group also demonstrated overlapping distributions of Panx1 and Panx 3 using confocal microscopy, and an interaction by immunoprecipitation. The extent of Panx1 and Panx3 co-precipitation was modulated by the glycosylation state of Panx1, but the physiological implications of these findings have not yet been fully elucidated.

Interestingly, Ambrosi etal. (2010) found that purified Panx1/Panx2 heteromeric channels from insect cells were unstable over time (present at $1 \mathrm{~h}$, but not $24 \mathrm{~h}$ post-purification). Additional experiments led the authors to suggest these findings could have resulted from size differences between Panx1 and Panx2, as well as experimentally identified differences in oligomeric symmetry (their study suggested that Panx1 forms hexamers while Panx2 forms octamers).

How Panx1 and Panx2 might functionally interact in cells remains to be determined. In the context of the nervous system, the distribution of Panx 2 appears to change from intracellular to cell surface during the course of hippocampal neurogenesis (Swayne et al., 2010), but whether Panx1 and Panx2 have overlapping distributions in mature neurons is currently unknown. Recent work investigating the role of Panxs in stroke recovery has demonstrated that knockout of both Panx1 and Panx2 improves histological and behavioral outcomes (Bargiotas et al., 2011; Kindo et al., 2011). Thus elucidation of the functional and physical relationships between members of the pannexin family will provide us with both fundamental and clinically relevant information. Although much progress has been made, there are still many unanswered questions relating to the crosstalk between Panx glycosylation and trafficking and the role of the Panx family interactions in this respect.

\section{P2X7 RECEPTORS}

It is perhaps not surprising that the physiological and pathophysiological roles of pannexins and $\mathrm{P} 2$ purinergic receptors are connected given the former is perhaps best known as an ATP release channel, and the latter act as receptors for ATP and its metabolite, ADP. Pelegrin and Surprenant (2006) first reported a physical and functional interaction between overexpressed Panx1 and P2X7 receptors in 2006. The authors also demonstrated that $\mathrm{P} 2 \mathrm{X} 7$ receptor activation in macrophage led to the opening of a large pore permeable to dye and IL- $1 \beta$ release. Based on their data, the authors concluded that Panx1 channels formed the large pore previously ascribed to $\mathrm{P} 2 \mathrm{X} 7$ receptors alone. Subsequent work by Locovei et al. (2007) in the Xenopus oocyte heterologous expression model further supported this work. They showed that P2X7 receptors formed a non-selective ion channel, but co-expression with Panx1 was necessary to form a larger channel referred to as the "death pore." Poornima et al. (2012) also reported an interaction between Panx1 and P2X7 receptors overexpressed in N2a cells. Recently, Kanjanamekanant et al. (2013) demonstrated an interaction between endogenous Panx1 and P2X7 receptor in human periodontal ligament cells using reciprocal immunoprecipitations, and found this interaction was strengthened following mechanical stress. Interestingly, Xu et al. (2012) observed a functional interaction only between Panx1 and the P2X7a receptor splice variant using dye uptake studies in overexpressing HEK293 cells. It now appears that such a Panx1-P2X7 receptor complex may also involve P2X4 receptor components in some cell types, as Hung et al. (2013) recently co-precipitated these three proteins from immortalized gingival epithelial cells.

Extending on the earlier findings by Pelegrin and colleagues, in the J774 monocyte macrophage cell line derived from a BALB/C mouse tumor, Iglesias et al. (2008) showed that Panxl activation was tightly coupled to $\mathrm{P} 2 \mathrm{X} 7$ receptor activation via a Panx1/P2X7 receptor complex involving a Src family tyrosine kinase (SFK). This group demonstrated interaction between the endogenously expressed proteins and were able to block the functional interaction with a membrane permanent TAT-P2X7 peptide targeting the $\mathrm{SH} 3$ domain of the $\mathrm{P} 2 \mathrm{X} 7$ receptor. Interestingly, Weilinger et al. (2012) have further linked SFKs more directly to Panx1 function using a Panx1 C-terminal competitive peptide strategy; however a physical interaction between the two proteins has not yet been illustrated. Alberto et al. (2013) observed conflicting findings with respect to the Panx1-P2X7 receptor coupling; in primary mouse and rat peritoneal macrophage cultures, RNAi targeting Panx1, as well as probenecid and carbenoxolone treatment to block Panx1, had no effect on ATP-induced P2X7 currents. It should be noted that these two studies used substantially different recording solutions. More importantly, there are likely substantial differences arising from the use of two different macrophage models. Macrophages are found in all tissues. As a result of their extreme inherent plasticity, these distinct tissue-subsets have a high level of diversity in terms of gene expression and functional capabilities (Wynn et al., 2013). Even within peritoneal macrophages, it has been recently revealed that there are two physical, functionally and developmentally distinct subsets (Ghosn et al., 2010). Thus, the Panx1/P2X7 receptor relationship in macrophages is likely state- and subset-dependent. Moreover microglia, the macrophage-like resident immune cells of the brain, also possess a P2X7-Panx1 functional unit. Rigato et al. (2012) recently observed that microglial proliferation is dependent on P2X7 receptor and not Panx1, however, initial microglial activation and/or recruitment may still possess a Panx1 component.

\section{The inflammasome, $P 2 X 7$ receptors, and Panx1 in cytokine activation and immune cell recruitment}

Interestingly, Panxl has recently been linked to the inflammasome, a large cytoplasmic complex involved in cytokine activation and immune cell recruitment (Martinon et al., 2002, 2009). P2X7 receptors and Panx1 have been reported to be associated with inflammasomes in a variety of cell types (Silverman et al., 2009). As critical components of the inflammasome, Nod-like receptor proteins (NLRPs) link the detection of "danger signals" [or danger associated molecular pattern molecules (DAMP)], arising under scenarios such as metabolic stress, to proteolytic activation of the pro-inflammatory cytokines IL-1 $\beta$ and IL-18. Other key complex proteins include the adaptor protein ASC (Apoptosisassociated speck-like protein containing a CARD), and the inflammatory caspases- 1 and -11 . While $\mathrm{P} 2 \mathrm{X} 7$ receptors are established inflammasome components, a recent report (Silverman et al., 2009) in cortical neurons revealed the potential involvement of Panx1. Silverman and colleagues immunoprecipitated Panx1 from 
cultured primary cortical neurons. Major components of the neuronal inflammasome including the P2X7 receptor, NLRP1, ASC, caspase-1, caspase-11, and X-linked inhibitor of apoptosis protein (XIAP) co-precipitated with Panx1. Reciprocally, ASC co-precipitated Panx1 as well as NLRP1, caspase-1, caspase-11, and XIAP. The authors further showed that elevating extracellular potassium above the normal resting range opened Panx1 channels leading to caspase- 1 activation, and that this was sensitive to the Panxl blocker probenecid. They determined that potassiumdependent activation of Panx1 was independent of changes in the membrane potential, which suggested that stimulation of inflammasome signaling was mediated by an allosteric effect of potassium binding to Panx1.

Minkiewicz et al. (2013) recently described a novel inflammasome in human astrocytes. They detected NLRP2 protein in human astrocytes and investigated the putative involvement of Panx1 in an NLRP2-based astrocytic inflammasome. Immunoprecipitation of NLRP2 from human primary astrocyte cultures co-precipitated Panx1, ASC, caspase-1, and P2X7 receptor. Reciprocally Panx1, P2X7 receptor, NLRP2, and caspase-1 coprecipitated with ASC. A more recent study (Wang et al., 2013) showed that while overexpressed Panx1 and NLRP3, or Panx1 and P2X7 receptors co-precipitated, overexpressed ASC and Panx1 did not interact in HEK293T cells. Interestingly, there were no deficiencies in NLRP3-inflammasome activation in macrophage of Panx1 knock-out mice (Qu et al., 2011; Wang et al., 2013; but see, Hung et al., 2013).

Gulbrandsen and colleagues confirmed in vivo Panx1 involvement in the NLRP3 inflammasome. They found that blocking Panx1 channels in enteric neurons ameliorates some of the effects of experimental colitis, including neuronal death (Gulbransen et al., 2012). Further, enteric neuronal death was dependent on P2X7 receptor, ASC, and caspase function, but not that of NLRP3, implying that a separate Panx1-inflammasome complex may be involved. Therefore, whether Panx1 is universally involved in inflammasome complexes may be characterized by cell type specific NLRP expression and utilization. Furthermore, the precise functional role of the physical association between Panx1 and inflammasome components remains to be determined.

\section{POTASSIUM CHANNEL AUXILIARY SUBUNIT Kv $\beta 3$}

One of the initial Panxl interactome studies was performed by Bunse et al. (2005). They employed an E. coli two-hybrid system to search for potential Panxl interactors. This study identified the potassium channel accessory subunit, $\mathrm{K}_{v} \beta 3$ (Kcnab3) as a putative interactor with the Panxl C-terminus. $\mathrm{K}_{v} \beta 3$ interacts with the shaker related voltage-gated potassium channels $\mathrm{K}_{v} 1.1,1.3,1.5$, and 1.6 to modify voltage-dependent activation, and inactivation kinetics (Leicher et al., 1998; Bahring et al., 2004; Tipparaju etal., 2012). A follow-up study confirmed the Panx $1-\mathrm{K}_{v} \beta 3$ interaction in a double-overexpression system by coprecipitation for the tagged proteins. An additional functional investigation indicated that ectopically expressed Panx1 currents became somewhat desensitized to redox- and pharmacologicalbased inhibition upon co-expression of $\mathrm{K}_{v} \beta 3$ in oocytes (Bunse et al., 2009). The authors postulated that $K_{v} \beta 3$ is important for regulating Panxl channel function by modulating its sensitivity to redox potentials. Bunse et al. (2011) further confirmed redox modulation of Panx1 activity, however, the molecular mechanisms underlying this sensitivity remain unknown. This will likely prove to be important in pathological contexts such as stroke and hypoxia, where redox signaling plays an important role (reviewed in Valko et al., 2007).

\section{$\alpha$ 1D-ADRENORECEPTOR}

Because of the established role of Panxl in the release of ATP, a signaling molecule important for vasoconstriction, Billaud et al. (2011) performed Panxl immunoprecipitations from thoracodorsal resistance arteries to examine its role in vascular smooth muscle cell communication. They identified an interaction between endogenous Panxl and the $\alpha 1 \mathrm{D}$-adrenoreceptor. Further, they noted that ATP release via Panxl was necessary to facilitate phenylephrine-evoked $\alpha 1 \mathrm{D}$-adrenoreceptor-mediated vessel constriction. Moreover, results from a HEK293 expression system indicated a Panx1-dependent component to ATP release evoked by $\alpha 1 D$-adrenoreceptor activation (Sumi et al., 2010). Taken together, these studies indicate a mechanism for Panxl activation downstream of adrenoreceptor stimulation, and imply a role for this channel in systemic blood pressure regulation.

\section{CYTOSKELETAL PROTEINS}

Perhaps unsurprisingly, due to its known mechanosensitive nature, Panxl has recently been found to associate with cytoskeletal proteins. Bhalla-Gehi et al. (2010) initially noted a role of the actinbased microfilament cytoskeleton in the cell-surface trafficking and stabilization of Panx1. Further study revealed an interaction between ectopically expressed Panxl and actin. Interestingly, in vitro binding assays with purified proteins revealed the Panx 1 C-terminus as the region responsible for the direct interaction.

More recently, our group confirmed this Panxl-actin association with endogenous Panxl immunoprecipitations from a neuroblastoma cell line (Wicki-Stordeur and Swayne, 2013). Moreover, immunofluorescence and confocal microscopy illustrated co-localization of Panx1-EGFP with actin.

Our study also uncovered several novel Panx1 interactors. We performed immunoprecipitations from Panx1-EGFP expressing cells, coupled to mass spectrometry-based identification. From these, a putative association of Panx1 with actin-related protein 3 (Arp3) was revealed. This interaction was confirmed through endogenous Panx1 co-precipitations, and co-localization by immunofluorescence. Arp3 is a component of the large Arp2/3 actin-regulating complex involved in nucleation and branching of microfilaments (reviewed in Firat-Karalar and Welch, 2011). Because of its key role in controlling the dynamic actin cytoskeleton, the Arp2/3 complex is key in several cellular processes dependent on actin remodeling, such as filopodia (Korobova and Svitkina, 2008; Spillane et al., 2011) and lamellipodia (Ingerman et al., 2013) formation, cell migration (Sawa et al., 2003; Schaefer etal., 2008), and neurite outgrowth (Schaefer etal., 2008; Firat-Karalar et al., 2011).

Using gene ontology (GO) analysis we determined that $10 \%$ of the mass spectrometry-identified putative Panx1 interactors in neuroblastoma cells fell under a cytoskeleton classification. While most of these have yet to be validated, the large proportion of 
cytoskeletal interactors implies a significant role for the cytoskeleton in regulation of Panxl trafficking and function. Potentially further connecting Panxl with the cytoskeleton and other ion channels, a novel interaction between stomatin and Panx1 has also recently been identified that inhibits Panxl currents (Zhan et al., 2012). Much work will clearly be needed to begin to untangle the complexities of emerging Panx1 nexus.

\section{CONCLUDING REMARKS}

The Panx1 interactome is beginning to emerge, however, many key questions remain unanswered. For instance, which of the Panx1 interactions are direct, and which occur indirectly through other bridging proteins? At present, the Panx1-actin relationship stands alone as the only proven direct interaction. The functional significance of many of these interactions is also currently unknown. Moreover, questions arise regarding the tissue and cell-type specificity of these interactions. For example, the Panx1-inflammasome connection not only seems to depend on which NLRP is forming the complex, but also on the cell type in question. Finally, little is understood regarding alterations to the Panx1 interactome under pathophysiological conditions, such as stroke. In order to fill such knowledge gaps in our understanding of the role of Panx1 in both physiological and pathophysiological settings, the Panx1 interactome must be more fully elucidated and understood. In this way we will uncover key molecular players involved in Panxl regulation and function, and thus be able to consider Panx1 as a viable therapeutic target within clinical settings.

\section{AUTHOR CONTRIBUTIONS}

Leigh E. Wicki-Stordeur and Leigh A. Swayne wrote and revised the manuscript. Leigh E. Wicki-Stordeur created the Table and Figure. Both authors approve of the manuscript and its contents.

\section{ACKNOWLEDGMENTS}

Research in the Swayne lab is supported by NSERC Discovery, Heart and Stroke Foundation Partnership for Stroke Recovery, Canadian Foundation for Innovation and British Columbia Knowledge Development Fund grants awarded to Leigh A. Swayne. Leigh E. Wicki-Stordeur is supported by a Vanier Canada Graduate Scholarship (NSERC) and an A. James and Laurette Agnew Memorial Award. LEWS was previously supported by an NSERC CGSM, a Howard E. Petch research scholarship, an Edythe HembroffSchleicher graduate scholarship, and the Victoria Foundation Willard and Elva Dawson Fund.

\section{REFERENCES}

Alberto, A. V., Faria, R. X., Couto, C. G., Ferreira, L. G., Souza, C. A., Teixeira, P. C., et al. (2013). Is pannexin the pore associated with the P2X7 receptor? Naunyn Schmiedebergs Arch. Pharmacol. 386, 775-787. doi: 10.1007/s00210-013-0868-x

Ambrosi, C., Gassmann, O., Pranskevich, J. N., Boassa, D., Smock, A., Wang, J., et al. (2010). Pannexin 1 and Pannexin2 channels show quaternary similarities to connexons and different oligomerization numbers from each other. J. Biol. Chem. 285, 24420-24431. doi: 10.1074/jbc.M110.115444

Bahring, R., Vardanyan, V., and Pongs, O. (2004). Differential modulation of Kv1 channel-mediated currents by co-expression of Kvbeta3 subunit in a mammalian cell-line. Mol. Membr. Biol. 21, 19-25. doi: 10.1080/09687680310001597749

Baranova, A., Ivanov, D., Petrash, N., Pestova, A., Skoblov, M., Kelmanson, I., etal. (2004). The mammalian pannexin family is homologous to the invertebrate innexin gap junction proteins. Genomics 83, 706-716. doi: 10.1016/j.ygeno.2003.09.025
Bargiotas, P., Krenz, A., Hormuzdi, S. G., Ridder, D. A., Herb, A., Barakat, W., et al. (2011). Pannexins in ischemia-induced neurodegeneration. Proc. Natl. Acad. Sci. U.S.A. 108, 20772-20777. doi: 10.1073/pnas.1018262108

Bargiotas, P., Krenz, A., Monyer, H., and Schwaninger, M. (2012). Functional outcome of pannexin-deficient mice after cerebral ischemia. Channels 6, 453-456. doi: $10.4161 /$ chan. 22315

Bhalla-Gehi, R., Penuela, S., Churko, J. M., Shao, Q., and Laird, D. W. (2010). Pannexin1 and pannexin3 delivery, cell surface dynamics, and cytoskeletal interactions. J. Biol. Chem. 285, 9147-9160. doi: 1074/jbc.M109.082008

Billaud, M., Lohman, A. W., Straub, A. C., Looft-Wilson, R., Johnstone, S. R., Araj, C. A., etal. (2011). Pannexin1 regulates alphal-adrenergic receptor-mediated vasoconstriction. Circ. Res. 109, 80-85. doi: 10.1161/CIRCRESAHA.110.237594 Bruzzone, R., Barbe, M. T., Jakob, N. J., and Monyer, H. (2005). Pharmacological properties of homomeric and heteromeric pannexin hemichannels expressed in Xenopus oocytes. J. Neurochem. 92, 1033-1043. doi: 10.1111/j.14714159.2004.02947.x

Bruzzone, R., Hormuzdi, S. G., Barbe, M. T., Herb, A., and Monyer, H. (2003). Pannexins, a family of gap junction proteins expressed in brain. Proc. Natl. Acad. Sci. U.S.A. 100, 13644-13649.

Bunse, S., Haghika, A., Zoidl, G., and Dermietzel, R. (2005). Identification of a potential regulator of the gap junction protein pannexin1. Cell Commun. Adhes. 12, 231-236. doi: 10.1080/15419060500511834

Bunse, S., Locovei, S., Schmidt, M., Qiu, F., Zoidl, G., Dahl, G., et al. (2009). The potassium channel subunit Kvbeta3 interacts with pannexin 1 and attenuates its sensitivity to changes in redox potentials. FEBS J. 276, 6258-6270. doi: 10.1111/j.1742-4658.2009.07334.x

Bunse, S., Schmidt, M., Hoffmann, S., Engelhardt, K., Zoidl, G., and Dermietzel, R. (2011). Single cysteines in the extracellular and transmembrane regions modulate pannexin 1 channel function. J. Membr. Biol. 244, 21-33. doi: 10.1007/s00232011-9393-3

Cowan, K. N., Langlois, S., Penuela, S., Cowan, B. J., and Laird, D. W. (2012). Pannexin1 and Pannexin3 exhibit distinct localization patterns in human skin appendages and are regulated during keratinocyte differentiation and carcinogenesis. Cell Commun. Adhes. 19, 45-53. doi: 10.3109/15419061.2012.712575

Diezmos, E. F., Sandow, S. L., Markus, I., Shevy Perera, D., Lubowski, D. Z., King, D. W., et al. (2013). Expression and localization of pannexin-1 hemichannels in human colon in health and disease. Neurogastroenterol. Motil. 25, e395-e405. doi: 10.1111/nmo.12130

Dvoriantchikova, G., Ivanov, D., Barakat, D., Grinberg, A., Wen, R., Slepak, V. Z., et al. (2012). Genetic ablation of Pannexinl protects retinal neurons from ischemic injury. PLoS ONE 7:e31991. doi: 10.1371/journal.pone.0031991

Firat-Karalar, E. N., Hsiue, P. P., and Welch, M. D. (2011). The actin nucleation factor JMY is a negative regulator of neuritogenesis. Mol. Biol. Cell 22, 4563-4574. doi: 10.1091/mbc.E11-06-0585

Firat-Karalar, E. N., and Welch, M. D. (2011). New mechanisms and functions of actin nucleation. Curr. Opin. Cell Biol. 23, 4-13. doi: 10.1016/j.ceb.2010.10.007

Ghosn, E. E., Cassado, A. A., Govoni, G. R., Fukuhara, T., Yang, Y., Monack, D. M., et al. (2010). Two physically, functionally, and developmentally distinct peritoneal macrophage subsets. Proc. Natl. Acad. Sci. U.S.A. 107, 2568-2573. doi: 10.1073/pnas.0915000107

Gulbransen, B. D., Bashashati, M., Hirota, S. A., Gui, X., Roberts, J. A., MacDonald, J. A., et al. (2012). Activation of neuronal P2X7 receptor-pannexin-1 mediates death of enteric neurons during colitis. Nat. Med. 18, 600-604. doi: 10.1038/nm.2679

Hung, S. C., Choi, C. H., Said-Sadier, N., Johnson, L., Atanasova, K. R., Sellami, H., et al. (2013). P2X4 assembles with P2X7 and pannexin-1 in gingival epithelial cells and modulates ATP-induced reactive oxygen species production and inflammasome activation. PLoS ONE 8:e70210. doi: 10.1371/journal.pone. 0070210

Iglesias, R., Locovei, S., Roque, A., Alberto, A. P., Dahl, G., Spray, D. C., et al. (2008). P2X7 receptor-Pannexin1 complex: pharmacology and signaling. Am. J. Physiol. Cell Physiol. 295, C752-C760. doi: 10.1152/ajpcell.00228.2008

Ingerman, E., Hsiao, J. Y., and Mullins, R. D. (2013). Arp2/3 complex ATP hydrolysis promotes lamellipodial actin network disassembly but is dispensable for assembly. J. Cell Biol. 200, 619-633. doi: 10.1083/jcb.201211069

Kanjanamekanant, K., Luckprom, P., and Pavasant, P. (2013). P2X7 receptorPannexin1 interaction mediates stress-induced interleukin-1 beta expression in human periodontal ligament cells. J. Periodontal. Res. doi: 10.1111/jre.12139 [Epub ahead of print]. 
Kanneganti, T. D., Lamkanfi, M., Kim, Y. G., Chen, G., Park, J. H., Franchi, L., et al. (2007). Pannexin-1-mediated recognition of bacterial molecules activates the cryopyrin inflammasome independent of Toll-like receptor signaling. Immunity 26, 433-443. doi: 10.1016/j.immuni.2007.03.008

Kindo, M., Gerelli, S., Billaud, P., and Mazzucotelli, J. P. (2011). Flash pulmonary edema in an orthotopic heart transplant recipient. Interact. Cardiovasc. Thorac. Surg. 12, 323-325. doi: 10.1510/icvts.2010.254755

Korobova, F., and Svitkina, T. (2008). Arp2/3 complex is important for filopodia formation, growth cone motility, and neuritogenesis in neuronal cells. Mol. Biol. Cell 19, 1561-1574. doi: 10.1091/mbc.E07-09-0964

Koval, M. (2006). Pathways and control of connexin oligomerization. Trends Cell Biol. 16, 159-166. doi: 10.1016/j.tcb.2006.01.006

Lai, C. P., Bechberger, J. F., and Naus, C. C. (2009). Pannexin2 as a novel growth regulator in C6 glioma cells. Oncogene 28, 4402-4408. doi: 10.1038/onc.2009.283

Lai, C. P., Bechberger, J. F., Thompson, R. J., MacVicar, B. A., Bruzzone, R., and Naus, C. C. (2007). Tumor-suppressive effects of pannexin 1 in C6 glioma cells. Cancer Res. 67, 1545-1554. doi: 10.1158/0008-5472.CAN-06-1396

Leicher, T., Bahring, R., Isbrandt, D., and Pongs, O. (1998). Coexpression of the KCNA3B gene product with Kv1.5 leads to a novel A-type potassium channel. J. Biol. Chem. 273, 35095-35101. doi: 10.1074/jbc.273.52.35095

Locovei, S., Scemes, E., Qiu, F., Spray, D. C., and Dahl, G. (2007). Pannexin1 is part of the pore forming unit of the P2X(7) receptor death complex. FEBS Lett. 581, 483-488. doi: 10. 1016/j.febslet.2006.12.056

MacVicar, B. A., and Thompson, R. J. (2009). Non-junction functions of pannexin-1 channels. Trends Neurosci. 33, 93-102. doi: 10.1016/j.tins.2009.11.007

Martinon, F., Burns, K., and Tschopp, J. (2002). The inflammasome: a molecular platform triggering activation of inflammatory caspases and processing of proILbeta. Mol. Cell 10, 417-426. doi: 10.1016/S1097-2765(02)00599-3

Martinon, F., Mayor, A., and Tschopp, J. (2009). The inflammasomes: guardians of the body. Annu. Rev. Immunol. 27, 229-265. doi: 10.1146/annurev.immunol.021908.132715

Minkiewicz, J., De Rivero Vaccari, J. P., and Keane, R. W. (2013). Human astrocytes express a novel NLRP2 inflammasome. Glia 61, 1113-1121. doi: 10.1002/glia.22499

Panchin, Y., Kelmanson, I., Matz, M., Lukyanov, K., Usman, N., and Lukyanov, S. (2000). A ubiquitous family of putative gap junction molecules. Curr. Biol. 10, R473-R474. doi: 10.1016/S0960-9822(00)00576-5

Pelegrin, P., and Surprenant, A. (2006). Pannexin-1 mediates large pore formation and interleukin-1beta release by the ATP-gated P2X7 receptor. EMBO J. 25, 50715082. doi: 10. 1038/sj.emboj.7601378

Penuela, S., Bhalla, R., Nag, K., and Laird, D. W. (2009). Glycosylation regulates pannexin intermixing and cellular localization. Mol. Biol. Cell 20, 4313-4323. doi: 10.1091/mbc.E09-01-0067

Penuela, S., Gyenis, L., Ablack, A., Churko, J. M., Berger, A. C., Litchfield, D. W., et al. (2012). Loss of pannexin 1 attenuates melanoma progression by reversion to a melanocytic phenotype. J. Biol. Chem. 287, 29184-29193. doi: 10.1074/jbc.M112.377176

Poornima, V., Madhupriya, M., Kootar, S., Sujatha, G., Kumar, A., and Bera, A. K. (2012). P2X7 receptor-pannexin 1 hemichannel association: effect of extracellular calcium on membrane permeabilization. J. Mol. Neurosci. 46, 585-594. doi: 10.1007/s12031-011-9646-8

Qu, Y., Misaghi, S., Newton, K., Gilmour, L. L., Louie, S., Cupp, J. E., et al. (2011). Pannexin-1 is required for ATP release during apoptosis but not for inflammasome activation. J. Immunol. 186, 6553-6561. doi: 10.4049/jimmunol.1100478

Rigato, C., Swinnen, N., Buckinx, R., Couillin, I., Mangin, J. M., Rigo, J. M., et al. (2012). Microglia proliferation is controlled by P2X7 receptors in a Pannexin-1independent manner during early embryonic spinal cord invasion. J. Neurosci. 32, 11559-11573. doi: 10.1523/JNEUROSCI.1042-12.2012

Sandilos, J. K., and Bayliss, D. A. (2012). Physiological mechanisms for the modulation of pannexin 1 channel activity. J. Physiol. 590, 6257-6266. doi: 10.1113/jphysiol.2012.240911

Sawa, M., Suetsugu, S., Sugimoto, A., Miki, H., Yamamoto, M., and Takenawa, T. (2003). Essential role of the C. elegans Arp2/3 complex in cell migration during ventral enclosure. J. Cell Sci. 116, 1505-1518. doi: 10.1242/jcs.00362

Schaefer, A. W., Schoonderwoert, V. T., Ji, L., Mederios, N., Danuser, G., and Forscher, P. (2008). Coordination of actin filament and microtubule dynamics during neurite outgrowth. Dev. Cell 15, 146-162. doi: 10.1016/j.devcel.2008.05.003
Silverman, W. R., De Rivero Vaccari, J. P., Locovei, S., Qiu, F., Carlsson, S. K., Scemes, E., et al. (2009). The pannexin 1 channel activates the inflammasome in neurons and astrocytes. J. Biol. Chem. 284, 18143-18151. doi: 10. 1074/jbc.M109. 004804

Sosinsky, G. E., Boassa, D., Dermietzel, R., Duffy, H. S., Laird, D. W., MacVicar, B., et al. (2011). Pannexin channels are not gap junction hemichannels. Channels 5, 193-197. doi: 10.4161/chan.5.3.15765

Spillane, M., Ketschek, A., Jones, S. L., Korobova, F., Marsick, B., Lanier, L., et al. (2011). The actin nucleating Arp2/3 complex contributes to the formation of axonal filopodia and branches through the regulation of actin patch precursors to filopodia. Dev. Neurobiol. 71, 747-758. doi: 10.1002/dneu.20907

Sumi, Y., Woehrle, T., Chen, Y., Yao, Y., Li, A., and Junger, W. G. (2010). Adrenergic receptor activation involves ATP release and feedback through purinergic receptors. Am. J. Physiol. Cell Physiol. 299, C1118-C1126. doi: 10.1152/ajpcell.00122.2010

Swayne, L. A., Sorbara, C. D., and Bennett, S. A. (2010). Pannexin 2 is expressed by postnatal hippocampal neural progenitors and modulates neuronal commitment. J. Biol. Chem. 285, 24977-24986. doi: 10.1074/jbc.M110.130054

Thompson, R. J., Zhou, N., and MacVicar, B. A. (2006). Ischemia opens neuronal gap junction hemichannels. Science 312, 924-927. doi: 10.1126/science.1126241

Tipparaju, S. M., Li, X. P., Kilfoil, P. J., Xue, B., Uversky, V. N., Bhatnagar, A., et al. (2012). Interactions between the C-terminus of Kv1.5 and Kvbeta regulate pyridine nucleotide-dependent changes in channel gating. Pflugers Arch. 463, 799-818. doi: 10.1007/s00424-012-1093-z

Valko, M., Leibfritz, D., Moncol, J., Cronin, M. T., Mazur, M., and Telser, J. (2007). Free radicals and antioxidants in normal physiological functions and human disease. Int. J. Biochem. Cell Biol. 39, 44-84. doi: 10.1016/j.biocel.2006. 07.001

Wang, H., Xing, Y., Mao, L., Luo, Y., Kang, L., and Meng, G. (2013). Pannexin-1 influences peritoneal cavity cell population but is not involved in NLRP3 inflammasome activation. Protein Cell 4, 259-265. doi: 10.1007/s13238-013-2114-1

Weilinger, N. L., Tang, P. L., and Thompson, R. J. (2012). Anoxia-induced NMDA receptor activation opens pannexin channels via Src family kinases. J. Neurosci. 32, 12579-12588. doi: 10.1523/JNEUROSCI.1267-12.2012

Wicki-Stordeur, L. E., Boyce, A. K., and Swayne, L. A. (2013). Analysis of a pannexin 2-pannexin 1 chimeric protein supports divergent roles for pannexin C-termini in cellular localization. Cell Commun. Adhes. 20, 73-79. doi: 10.3109/15419061.2013.791681

Wicki-Stordeur, L. E., and Swayne, L. A. (2013). Panxl regulates neural stem and progenitor cell behaviours associated with cytoskeletal dynamics and interacts with multiple cytoskeletal elements. Cell Commun. Signal. 11, 62. doi: 10.1186/1478-811X-11-62

Wynn, T. A., Chawla, A., and Pollard, J. W. (2013). Macrophage biology in development, homeostasis and disease. Nature 496, 445-455. doi: 10.1038/nature12034

Xu, X. J., Boumechache, M., Robinson, L. E., Marschall, V., Gorecki, D. C., Masin, M., et al. (2012). Splice variants of the P2X7 receptor reveal differential agonist dependence and functional coupling with pannexin-1. J. Cell Sci. 125, 3776-3789. doi: 10.1242/jcs.099374

Zhan, H., Moore, C. S., Chen, B., Zhou, X., Ma, X-M., Ijichi, K., et al. (2012). Stomatin inhibits pannexin-1-mediated whole-cell currents by interacting with its carboxyl terminal. PLoS ONE 7:e39489. doi: 10.1371/journal.pone.0039489

Conflict of Interest Statement: The authors declare that the research was conducted in the absence of any commercial or financial relationships that could be construed as a potential conflict of interest.

Received: 04 December 2013; paper pending published: 16 December 2013; accepted: 23 December 2013; published online: 08 January 2014.

Citation: Wicki-Stordeur LE and Swayne LA (2014) The emerging Pannexin 1 signalome: a new nexus revealed?. Front. Cell. Neurosci. 7:287. doi: 10.3389/fncel.2013. 00287

This article was submitted to the journal Frontiers in Cellular Neuroscience.

Copyright $(2014$ Wicki-Stordeur and Swayne. This is an open-access article distributed under the terms of the Creative Commons Attribution License (CC BY). The use, distribution or reproduction in other forums is permitted, provided the original author(s) or licensor are credited and that the original publication in this journal is cited, in accordance with accepted academic practice. No use, distribution or reproduction is permitted which does not comply with these terms. 